\title{
Angiotensin-Converting Enzyme 2 Attenuates Bleomycin-Induced Lung Fibrosis in Mice
}

\author{
Lifang Wang ${ }^{a, b, e}$ Yuxiang Wang ${ }^{c, d}$ Tuo Yang ${ }^{a, b, f} \quad$ Yanfei Guo ${ }^{a, b} \quad$ Tieying Sun ${ }^{a, b}$ \\ aPeking University, the Fifth School of Clinical Medicine, Beijing, ${ }^{b}$ Department of Respiratory and \\ Critical Care Medicine, Beijing Hospital, Ministry of Health, Beijing, 'Peking University, the Third School \\ of Clinical Medicine, Beijing, dDepartment of Pathology, Peking University Health Science Center, \\ Beijing, China; ${ }^{e}$ Current affiliation: China Japan Friendship Hospital (Beijing, China); ${ }^{\mathrm{f} C u r r e n t}$ affiliation: \\ University of Pittsburgh, Pittsburgh, USA
}

\author{
Key Words \\ Lung fibrosis • Alveolitis • Bleomycin • RAS • ACE2
}

\begin{abstract}
Background: Local renin-angiotensin system (RAS) activation has been shown to play an important role in the pathogenesis of idiopathic pulmonary fibrosis (IPF). It has been reported that angiotensin-converting enzyme 2 (ACE2) could inhibit RAS-mediated epithelial injury and fibrogenesis and that ACE2 deficiency could aggravate acute and chronic lung injury. Through research, it could be deduced that ACE2 could protect against pulmonary fibrosis as a therapeutic target. Methods: Time-course analysis of the pathological characteristics of bleomycin-induced lung fibrosis was undertaken in a mouse model, and the effect of exogenous ACE2 on lung fibrosis was studied. Immunohistchemistry (IHC) staining and western blot (WB) testing for AGT and ACE2 were performed to evaluate the regulation of local RAS. TUNEL staining was used to observe epithelial apoptosis. Leukocyte common antigen (LCA) and pulmonary surfactant-associated protein A (SP-A) IHC staining and WB testing were performed to assess the inflammatory response and epithelial regeneration. Masson's staining and a hydroxyproline assay were performed to examine collagen deposition. IHC staining and WB testing for TGF- $\beta 1$ and $\alpha$-SMA were performed to investigate the regulation of pro-fibrotic cytokines and the activation of fibroblasts. Results: Exogenous ACE2 attenuated bleomycin-induced lung fibrosis by reversing the reduction of local ACE2 and by suppressing the elevation of AGT. ACE2 decreased the apoptosis index and LCA levels and ameliorated the dynamic change in SP-A level, thus protecting against epithelial injury. Reductions of TGF- $\beta 1$ and $\alpha$-SMA were also found in ACE2-treated mice, indicating the inhibition of fibrogenesis. Conclusion: ACE2 attenuated bleomycin-induced lung fibrosis as an anti-inflammatory, antiapoptotic and anti-fibrotic agent, and it might be a promising therapeutic target for IPF.
\end{abstract}

Copyright (C) 2015 S. Karger AG, Basel

Tieying Sun, Ph.D.

KARGER 125
Department of Respiratory and Critical Care Medicine, Beijing Hospital Ministry of Health, No. 1 Dahua Road, Dong Dan, Beijing 100730 (China)

Tel. +86-10-85136242, E-Mail suntieying@126.com 


\section{Cellular Physiology Cell Physiol Biochem 2015;36:697-711 \\ \begin{tabular}{l|l} 
DOI: 10.1159/000430131 & $\begin{array}{l}\text { C 2015 S. Karger AG, Basel } \\
\text { www.karger.com/cpb }\end{array}$ \\
\hline
\end{tabular}}

\section{Introduction}

Idiopathic pulmonary fibrosis (IPF) is a progressive and fatal pulmonary interstitial disease of unknown etiology. Patients suffer from deteriorating lung function, which usually leads to respiratory failure and right-sided heart failure as lethal complications [1]. The median survival with IPF is 3 to 5 years, comparable to lung cancer [2]. Moreover, practically no effective therapy has yet been established. Because IPF incidence has been found to be rising [3], there is a pressing need to explore new insights into the pathogenesis and treatment of the disease.

Recurrent epithelial injury and subsequent fibrotic wound repair are key factors in the pathogenesis of IPF [4]. Epithelial injury stimulates the release of pro-apoptotic, proinflammatory and pro-fibrotic cytokines, such as angiotensin II (AngII), IL-1 $\beta$, TGF- $\beta 1$, etc. $[5,6]$, which can further aggravate alveolar structure derangement, subsequently triggering fibroblast activation and excessive collagen synthesis, which gradually result in fibrotic lung remodeling [7].

The local renin-angiotensin system (RAS) of the lung has been indicated as a determinant in the pathogenesis of IPF. The local RAS has a major impact on both epithelial injury and the pro-fibrotic repair response. AngII and its precursor angiotensin (AGT), which are produced through the activation of the local RAS, become abundant in IPF lungs [8]. AGT and AngII are excessively secreted from apoptotic alveolar epithelial cells in IPF [9], and these cytokines are indispensable for epithelial cell apoptosis [10]. In addition, AngII has been shown to stimulate pro-inflammatory chemokines, adhesion molecules, proinflammatory transcription factors and superoxide production [11], and it is considered to be a key mediator of inflammation, contributing to epithelial injury [12,13]. Moreover, overexpression of AGT and AngII in (myo)fibroblasts isolated from IPF lungs [9] was found to interact with TGF- $\beta 1$, which is the strongest pro-fibrotic factor, in an "AGT/ANGII-TGF- $\beta 1$ autocrine loop" [14], to promote fibrogenesis.

Recent articles have revealed that activation of the local RAS is accompanied by weakened negative feedback and is modulated by a key negative regulator: angiotensin converting enzyme 2 (ACE2). As shown in Figure 1, ACE2 not only plays a protective role by degrading local AngII, but its product Ang1-7 also exerts anti-apoptotic, anti-inflammatory and anti-fibrotic effects through the ACE2-Ang1-7-Mas pathway [15-17]. ACE2 is mainly detected in the lung epithelium and vascular endothelium, while it is significantly decreased in IPF lungs [18]. Therefore, to compensate for the deficiency in ACE2, negative control of alveolar epithelium injury and fibrogenesis might be necessary, thus providing a potential target for therapies for IPF.

\section{Materials and Methods}

Chemicals and reagents

Bleomycin (BLM) was acquired from Nippon Kayaku Co. (Tokyo, Japan). A hydroxyproline (HYP) analysis kit was acquired from Sigma-Aldrich (Shanghai, China). A hematoxylin-eosin staining (H\&E) kit was acquired from Lanbio (Beijing, China). A Trichrome stain (Masson) kit was acquired from Leagene (Beijing, China). A streptavidin-peroxidase (SP) kit was acquired from Biostest Co. (Beijing, China). A terminal deoxynucleotidyl transferase dUTP nick-end labeling (TUNEL) kit was acquired from Roche (Indianapolis, IN, USA). A Mammalian Cell Extraction Kit was acquired from Biovision (Los Angeles, CA, USA). PMSF, TBS, SDS-PAGE gel, TEMED, TBST, and BCA protein assay kit were acquired from Dorun Co. (Beijing, China). HRPconjugated goat anti-rabbit and anti-mouse IgG and HRP-conjugated mouse anti-goat IgG antibodies were acquired from Abmart (Shanghai, China). Recombinant mouse ACE2 was acquired from Sino Biological Inc. (Beijing, China). AGT, ACE2, pulmonary surfactant-associated protein A (SP-A), leukocyte common antigen (LCA/CD45), TGF- $\beta 1, \alpha$-smooth muscle actin ( $\alpha$-SMA) antibodies were acquired from Abcam (Cambridge, MA, USA).

\section{KARGER}




\section{Cellular Physiology \\ Cell Physiol Biochem 2015;36:697-711 \\ \begin{tabular}{l|l}
${ }$ and Biochemistry Published online: May 21, $2015 }$ & $\begin{array}{l}\text { ( ) 2015 S. Karger AG, Bas } \\
\text { www.karger.com/cpb }\end{array}$ \\
\hline
\end{tabular}}

Wang et al.: ACE2 Attenuates Lung Fibrosis

Fig. 1. The local lung renin-angiotensin system

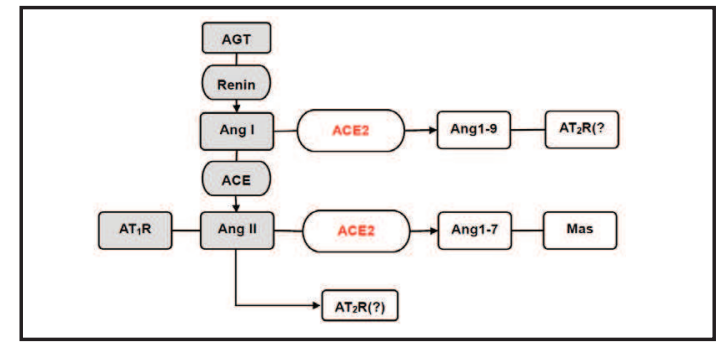

Table 1. Szapiel's scoring of alveolitis and fibrosis [19]

\begin{tabular}{|c|c|c|c|}
\hline & Score & Grade & Pathological features \\
\hline \multirow[t]{4}{*}{ Alveolitis } & 1 & - & No apparent alveolitis \\
\hline & 2 & + & $\begin{array}{l}\text { Mild alveolitis with pulmonary interstitial edema, inflammatory cell infiltration, and } \\
\text { alveolar septum thickening, with lesions only local or limited to the subpleural area, } \\
\text { which do not exceed } 20 \% \text { of the lung }\end{array}$ \\
\hline & 3 & ++ & $\begin{array}{l}\text { Moderate alveolitis with the subpleural area more obvious, with the involved area more } \\
\text { than } 20 \% \text { but less than } 50 \% \text { of the lung }\end{array}$ \\
\hline & 4 & +++ & $\begin{array}{l}\text { Severe alveolitis with lesions more than } 50 \% \text { of the lung, with inflammatory cells inside } \\
\text { the alveolar cavity and consolidation changes }\end{array}$ \\
\hline \multirow[t]{4}{*}{ Fibrosis } & 1 & - & No apparent fibrosis \\
\hline & 2 & + & $\begin{array}{l}\text { Mild fibrosis with minimal fibrous thickening of the alveolar septa, which is only local or } \\
\text { limited to the subpleural area and does not exceed } 20 \% \text { of the lung }\end{array}$ \\
\hline & 3 & ++ & $\begin{array}{l}\text { Moderate fibrosis with the subpleural area more serious, with fibrous bands or small } \\
\text { fibrous masses and an involved area more than } 20 \% \text { but less than } 50 \% \text { of the lung; }\end{array}$ \\
\hline & 4 & +++ & $\begin{array}{l}\text { Severe fibrosis with lesions more than } 50 \% \text { of the lung, distortion of the alveolar } \\
\text { structure, large fibrous areas, (myo)fibroblast foci and honeycomb changes might be } \\
\text { observed }\end{array}$ \\
\hline
\end{tabular}

Animal model

All of the experiments were performed in accordance with National Institutes of Health guidelines, and the protocols were approved by the Medicine Subcommittee on Research Animal Care of Peking University Health Science Center. One hundred twenty male C57BL/6J mice, eight weeks old and weighing 17-20 g upon arrival, were purchased from the Animal Center of Peking University (Beijing, China). The mice were provided ad libitum access to food and water. The animals were randomly divided into 4 groups as: (1) Saline group: $0.9 \%$ saline $(200 \mu \mathrm{L})$ injection via the tail vein; (2) ACE2 group: a single intraperitoneal injection of ACE2 (0.2 mg/kg); (3) BLM group: a single injection of bleomycin at $150 \mathrm{mg} / \mathrm{kg}$ via the tail vein; and (4) BLM+ACE2 group: an injection of bleomycin at $150 \mathrm{mg} / \mathrm{kg}$ via the tail vein, followed by an intraperitoneal injection of ACE2 at $0.2 \mathrm{mg} / \mathrm{kg}$. After administration, ten animals randomly selected from each group were euthanized on days 7,14 and 28 by cervical dislocation.

\section{Lung histopathology}

Right lungs were removed and fixed overnight in $10 \%$ formalin and were embedded in paraffin and cut into $5 \mu$ m-thick sections. The H\&E staining method was used to investigate alveolitis and fibrosis. The Masson's trichrome staining method was performed to reveal collagen deposition (blue staining). The severity of pathological changes was scored according to Szapiel's method (Table 1) [19]. Double-blind evaluation of alveolitis and fibrosis was conducted by two pathologists, and the mean score was considered as the alveolitis and fibrosis scores for each sample.

\section{Measurement of hydroxyproline concentrations}

Left lower lobes were harvested in liquid nitrogen. The lung tissue was hydrolyzed, followed by derivation using the HYP analysis kit (Sigma). The collagen content was measured and analyzed by ultraviolet spectrophotometry, using the procedure indicated by the manufacturer. The HYP content is reported as $\mu \mathrm{g} / \mathrm{mg}$ frozen tissue.

TUNEL assay

Paraffin-embedded lung sections were used for TUNEL staining, according to manufacturer's instructions (Roche). The sections were stained with diaminobenzidine (DAB) and counterstained with 


\section{Cellular Physiology Cell Physiol Biochem 2015;36:697-711

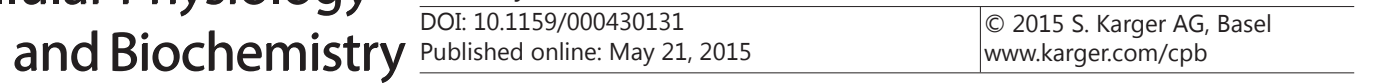 \\ Wang et al.: ACE2 Attenuates Lung Fibrosis}

hematoxylin. TUNEL-positive apoptotic cells exhibited brown nuclei. Five views were randomly selected on each section (40× magnification) to calculate the number of apoptotic cells. The apoptotic index (AI) was measured as a percentage of positive cells.

\section{Immunohistochemistry}

To achieve integrated detection of protein expression and quantification, sections obtained from paraffin-embedded samples were immunoassayed using the SP kit (Biostest), following the manufacturer's instructions (Biostest). Markers for the local RAS were detected by AGT and ACE2 immunolabeling. Epithelial repair was marked by SP-A immunostaining. Inflammatory cell infiltration was marked by LCA immunostaining. TGF- $\beta 1$ and $\alpha$-SMA were immunostained as markers of fibroblast activation. Sections were stained with DAB and counterstained with hematoxylin. Brown-stained cells were considered positive. Pictures were obtained, and the mean optical density (MOD) was measured using Image Pro Plus software, version 6.0, for the semiquantitative analysis of protein expression [20]. Five views were randomly selected on each section ( $400 \times$ magnification) using a high-power microscope, and "integrated optical density" (IOD) and "area sum" were measured. The results were recorded as MOD=IOD/area sum [21].

\section{Western blot analyses}

Left upper lungs were irrigated with saline. Quantitative western blot analysis was performed for the measurement of AGT, ACE2, LCA, SP-A, $\alpha$-SMA and TGF- $\beta 1$ expression in lung tissue. Proteins were extracted using the Mammalian Cell Extraction Kit, following the manufacturer's instructions (Biovision). The BCA protein assay kit (Dorun) was used to determine protein concentrations. Samples of equal amounts of protein were subjected to $12 \%$ SDS-PAGE on gel and then were transferred to PVDF membrane. After being blocked by milk in TBST, the membranes were incubated with primary antibodies against the target protein. After washing with TBST, the membranes were incubated in HRP-conjugated goat anti-rabbit and antimouse IgG and then washed. Proteins were detected by enhanced chemiluminescence and were quantified using density analysis normalized against GAPDH.

\section{Statistical analysis}

The data were analyzed using SPSS (Statistical Package for the Social Sciences) statistical software, version 19.0. Descriptive results are expressed as the mean \pm SEM. The Kruskal-Wallis test was used to analyze the ranked data of pulmonary alveolitis and pulmonary fibrosis. Quantitative data were analyzed by one-way ANOVA for multiple comparisons, followed by post-hoc comparison with the LSD test (equal variances assumed) or Dunnett's test (equal variances not assumed). $\mathrm{p}<0.05$ was considered statistically significant.

\section{Results}

\section{ACE2 attenuated bleomycin-induced alveolitis and fibrosis}

As shown in Figure 2, a single injection of bleomycin at the dose of $150 \mathrm{mg} / \mathrm{kg}$ via the tail vein in mice induced mild to moderate alveolitis $(2.60 \pm 0.39)$ on day $7(p<0.05$ compared with the Saline group). Lungs exhibited focal distribution of alveolitis that was predominantly subpleural and perivascular, in which the alveolar septa were mildly thickened with edema and inflammatory cell infiltration; no apparent fibrosis was observed. At the same time, administration of ACE2 did not significantly alter the pathological changes on day $7(B L M+A C E 2$ group vs. BLM group, $\mathrm{p}>0.05)$. On day 14 , the BLM group showed disease progression. Lungs exhibited moderate to severe alveolitis $(3.15 \pm 0.63)$ and moderate

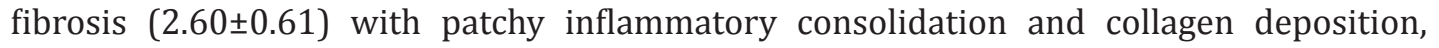
while the administration of ACE2 significantly attenuated both alveolitis (2.11 \pm 0.60$)$ and fibrosis (1.33 \pm 0.35$)(B L M+A C E 2$ group vs. BLM group, $\mathrm{p}<0.05)$. On day 28 , in the BLM group, alveolitis $(2.70 \pm 0.35)$ spontaneously resolved $(\mathrm{p}<0.05$ compared with the BLM group at day 14); however, derangement of the alveolar architecture continued, and fibrosis (2.70 \pm 0.48 ) persisted ( $p>0.05$ compared with the BLM group at day 14), characterized by diffuse, dense, thick collagen bundles and fibroblast foci. ACE2 noticeably reflected a long-term therapeutic 


\section{Cellular Physiology $\quad$ Cell Physiol Biochem 2015;36:697-711 \begin{tabular}{l|l} 
DOI: 10.1159/000430131 & $\begin{array}{l}\text { O 2015 S. Karger AG, Basel } \\
\text { www.karger.com/cpb }\end{array}$ \\
\hline
\end{tabular}

A

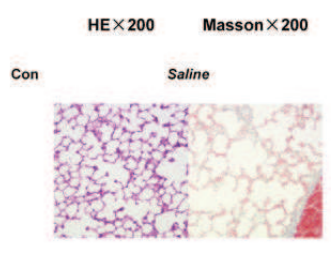

$B L M$
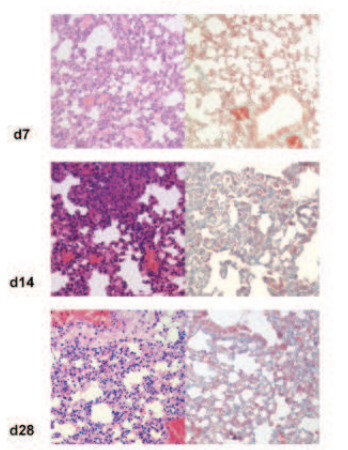

B

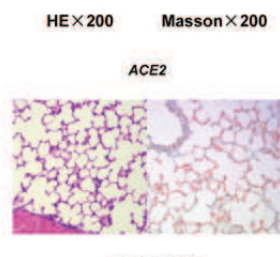

BLM+ACE2

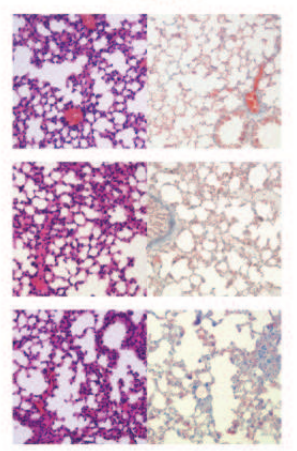

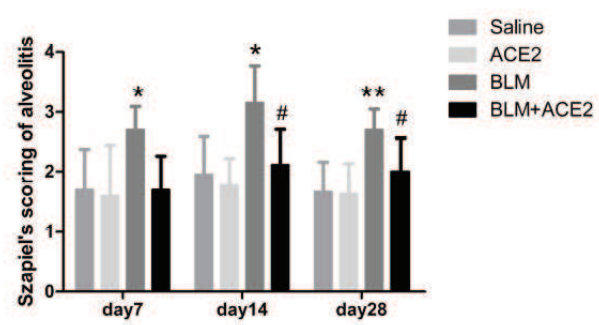

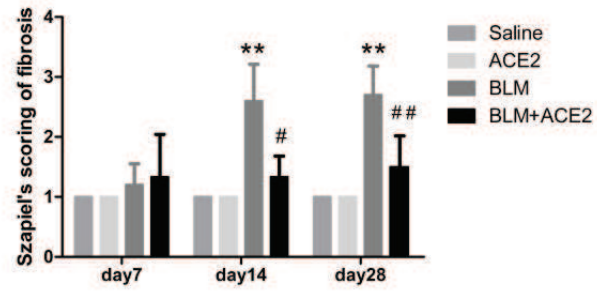

C

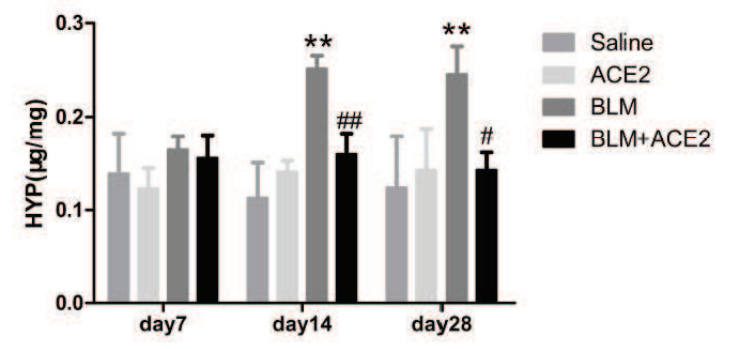

Fig. 2. The local lung renin-angiotensin system. ACE2 improved histological changes in bleomycin-induced lung fibrosis. Recombinant mouse ACE2 and bleomycin were administered on day 0. (A) Dynamic morphological changes in bleomycin-induced lung fibrosis are presented through H\&E staining (magnification 200x). Additionally, Masson's trichrome (magnification 200x) staining highlights collagen deposition (blue stained) appeared on day 14 and day 28 in BLM group. It has been proposed that ACE2 suppressed the progression of fibrogenesis to a mild condition over time. (B) Szapiel's scoring was obtained to quantify the degree of alveolitis and fibrosis and inhibitory potency of ACE2. (C) HYP concentration paralled pathological scoring of fibrosis. HYP increased in BLM group on day14 and day28 $(\mathrm{p}<0.05)$, and significantly reduced in BLM+ACE2 group $(\mathrm{p}<0.05)$. Data represent as means \pm SEM. ${ }^{*} \mathrm{p}<0.05$ when compared with the Saline group, ${ }^{* *} \mathrm{p}<0.01$ when compared with Saline group, \#p<0.05 when compared with BLM group, \#\# $<0.05$ when compared with BLM group. $\mathrm{n}=10$ in each group.

Table 2. HYP concentration and Szapiel's score of fibrosis in four groups

\begin{tabular}{lcccccc}
\hline \multirow{2}{*}{ groups } & \multicolumn{2}{c}{ Day7 } & \multicolumn{2}{c}{ Day14 } & \multicolumn{2}{c}{ Day28 } \\
& HYP $(\mu \mathrm{g} / \mathrm{mg})$ & fibrosis score & HYP $(\mu \mathrm{g} / \mathrm{mg})$ & fibrosis score & HYP $(\mu \mathrm{g} / \mathrm{mg})$ & fibrosis score \\
\hline Saline & $0.139 \pm 0.043$ & $1 \pm 0$ & $0.113 \pm 0.038$ & $1 \pm 0$ & $0.024 \pm 0.055$ & $1 \pm 0$ \\
ACE2 & $0.123 \pm 0.022$ & $1 \pm 0$ & $0.141 \pm 0.012$ & $1 \pm 0$ & $0.143 \pm 0.044$ & $1 \pm 0$ \\
BLM & $0.165 \pm 0.014$ & $1.2 \pm 0.35$ & $0.252 \pm 0.014^{* *}$ & $2.6 \pm 0.61^{* *}$ & $0.246 \pm 0.030^{* *}$ & $2.7 \pm 0.48^{* *}$ \\
BLM+ACE2 & $0.156 \pm 0.024$ & $1.33 \pm 0.71$ & $0.160 \pm 0.022^{\# \#}$ & $1.33 \pm 0.35^{\#}$ & $0.143 \pm 0.019^{\#}$ & $1.50 \pm 0.52^{\# \#}$ \\
\hline
\end{tabular}




\section{Cellular Physiology Cell Physiol Biochem 2015;36:697-711 \begin{tabular}{l|l} 
DOI: 10.1159/000430131 & $\begin{array}{l}\text { O 2015 S. Karger AG, Bace } \\
\text { www.karger.com/cpb }\end{array}$ \\
and Biochemistry &
\end{tabular}

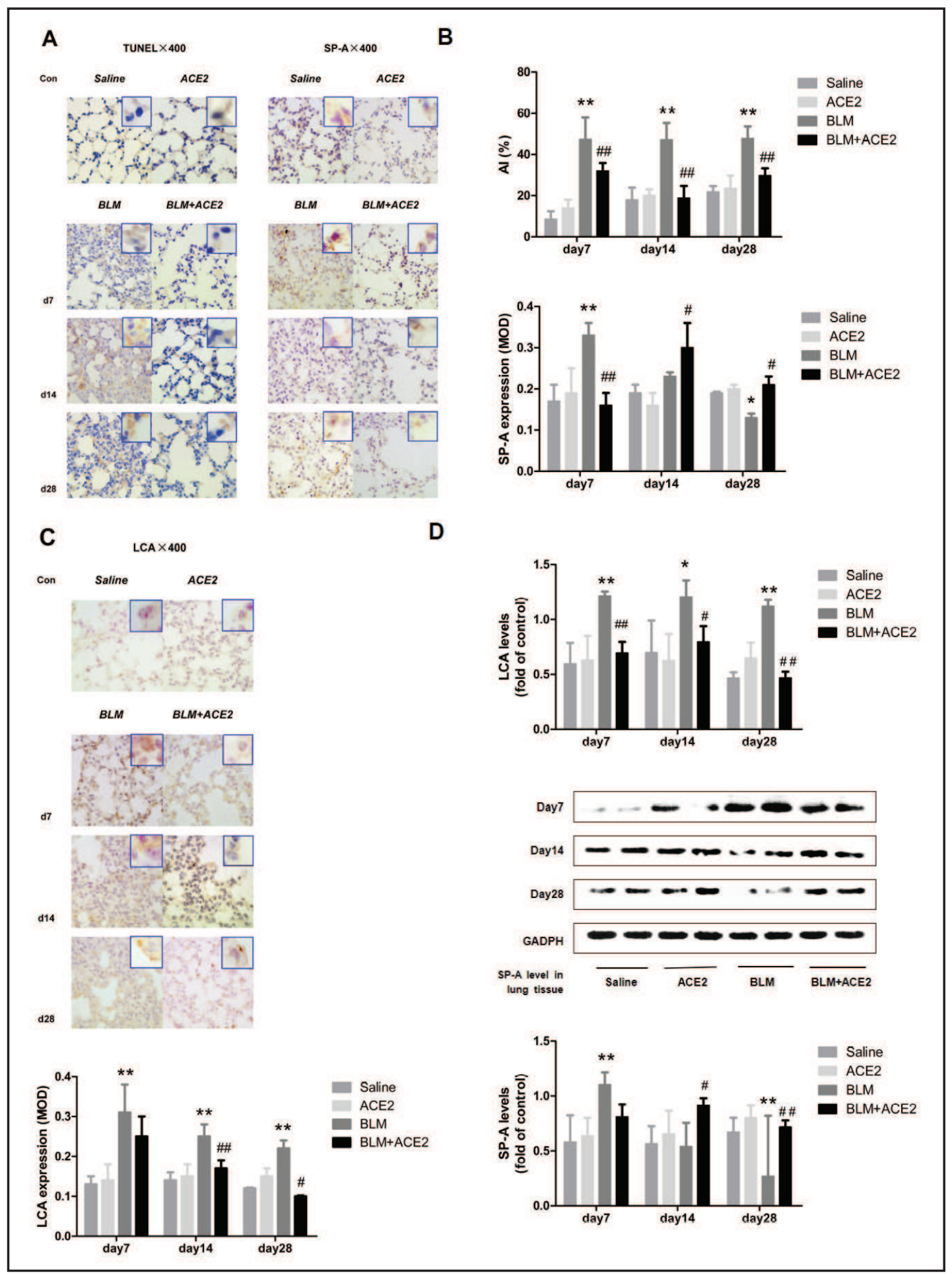

Fig. 3. ACE2 attenuated bleomycin-induced epithelial injury. In BLM group, cell density in lungs substantially increased from 7 to 14 days and slightly reduced on day 28 under direct microscopic visualization. (A) Apoptotic cells were brown stained by TUNEL assay (400×) and were widely distributed in distorted alveolar epithelium as well as regional inflammatory and fibrotic lesions in BLM group. SP-A stained for type II alveolar epithelial cells (400x), was enhanced during early stage of fibrogenesis and decreased during late stage of lung fibrosis. ACE2 reduced bleomycin-induced epithelial apoptosis, excessive proliferation, and progressive alveolar epithelial cell loss. (B) Apoptosis index (AI\%) and semiquantitative study of SP-A 


\section{Cellular Physiology Cell Physiol Biochem 2015;36:697-711

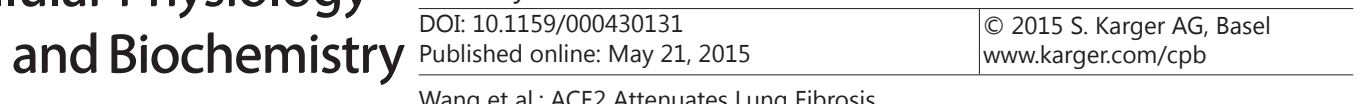

expression revealed ACE2's anti-apoptotic effect and modulated alveolar epithelium repair. (C) LCA determined by IHC was evident in the membrane of neutrophils, macrophages and lymphocytes (400×). Inflammatory cell infiltration was significantly inhibited by ACE2 throughout pathogenesis of bleomycin-induced lung fibrosis. (D) Western blot analysis of SP-A and LCA level in lung tissue. Quantitative studies comfirmed that ACE2 inhibited BLM-induced inadequate alveolar repair response and lung inflammation.*p<0.05 when compared with Saline group, ${ }^{* *} \mathrm{p}<0.01$ when compared with Saline group, $\# \mathrm{p}<0.05$ when compared with BLM group, \#\#p<0.05 when compared with BLM group.

effect on day 28, with sections in the BLM+ACE2 group presenting only mild alveolitis $(2.00 \pm 0.56, \mathrm{p}<0.05$ compared with $B L M$ group $)$ and significant attenuation of fibrosis $(1.50 \pm 0.52, \mathrm{p}<0.01$ compared with the BLM group). No signs of alveolitis or fibrosis were found in the Saline group or the ACE2 group among the different time points. In accordance with our pathological scoring of fibrosis (Table 2), the HYP concentration in the BLM group increased significantly from day 14 to day 28 ( $\mathrm{p}<0.05$ compared with the Saline group), and ACE2 significantly inhibited HYP deposition ( $\mathrm{p}<0.05$ compared with the BLM group at the same time point).

\section{Protective role of ACE2 in epithelium injury}

Epithelial injury was recognized as an early feature of bleomycin-induced fibrosis models characterized by epithelial apoptosis, followed by transient hyperplasia of type II alveolar epithelial cells and inflammatory cell infiltration (fig. 3). In the BLM group, apoptotic cells stained by TUNEL assay were mainly distributed along distorted airspace walls and in the areas of consolidation (AI $47.27 \% \pm 10.7 \%, 47.07 \% \pm 8.25 \%$, and $47.73 \% \pm 5.89 \%$ on days 7,14 , and 28 , respectively); at the same time, LCA-positive inflammatory cells in the lung exhibited prolonged patchy interstitial inflammation. In the BLM+ACE2 group, the apoptotic index (AI 31.78\% $\pm 4.03 \%, 18.8 \% \pm 5.88 \%$, and $29.68 \% \pm 3.61 \%$ on days 7,14 and 28 , respectively) dramatically decreased compared with the BLM group (all $\mathrm{p}<0.01$ at each time point), and LCA expression significantly decreased ( $\mathrm{p}<0.05$ compared with the BLM group at the same time point) by both IHC and western blot study. Moreover, as a marker specific to type II alveolar epithelial cells, SP-A expression increased noticeably in the BLM group on day 7 ( $\mathrm{p}<0.05$ compared with the Saline group) but tended to decrease on day 14 ( $\mathrm{p}=0.052$ compared with the BLM group on day 7) and significantly decreased on day 28 ( $\mathrm{p}<0.05$ compared with the BLM group on day14), while in the BLM+ACE2 group, the level of SP-A was relatively low on day 7 but at a higher level than in the BLM group on days and day 28 (both $p<0.05$ compared at the same time point). The results demonstrated that ACE2 inhibited early excessive epithelial cell proliferation, as well as subsequent excessive cell loss, as epithelial injury progressed. The findings together indicated that ACE2 had treatment effects on bleomycin-induced epithelial cell apoptosis and inflammation.

ACE2 inhibited pro-fibrotic cytokines and fibroblast activation of BLM-induced lung fibrosis

Previous results have shown that ACE2 attenuated the late-stage progression of lung fibrosis. Fibrogenesis was characterized by overexpression of pro-fibrotic cytokines and (myo)fibroblast activation. As shown in Figure 4, on days 14 and 28, TGF- $\beta 1$ expression emerged strongly and diffusely in alveolar epithelial cells, inflammatory cells and (myo) fibroblasts in the BLM group but was significantly weakened in the BLM+ACE2 group ( $\mathrm{p}<0.05$ compared with the BLM group at the same time point); otherwise, there were no significant differences in protein expression on day 7 among all of the groups ( $>>0.05)$. Consistent with the increase in TGF- $\beta 1$, activation of fibroblasts was indicated in the BLM group on days 14 and 28, marked by densely clustered expression of $\alpha$-SMA in the lung interstitium $(\mathrm{p}<0.05$ compared with the Saline group), and it significantly decreased in the BLM+ACE2 group ( $\mathrm{p}<0.05$ compared with the BLM group at the same time point). The results exhibited ACE2's inhibitory effects on fibroblast proliferation and myofibroblast transdifferentiation. 


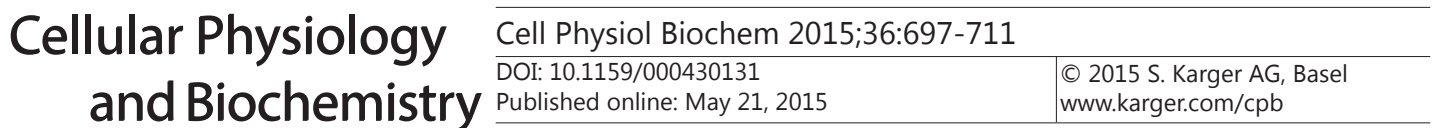 \\ Wang et al.: ACE2 Attenuates Lung Fibrosis}

A

A

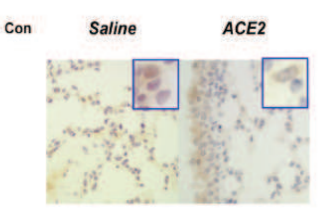

BLM BLM+ACE2

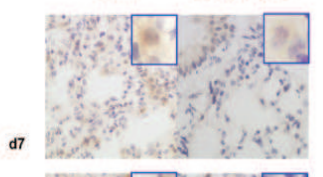

d7

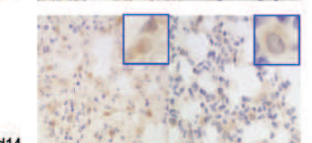

d14

d28

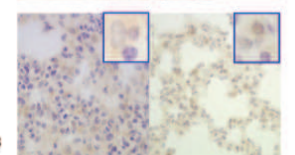

a $-\operatorname{SMA} \times 400$

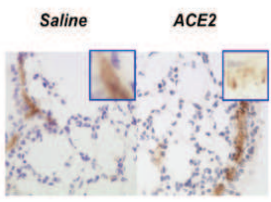

BLM
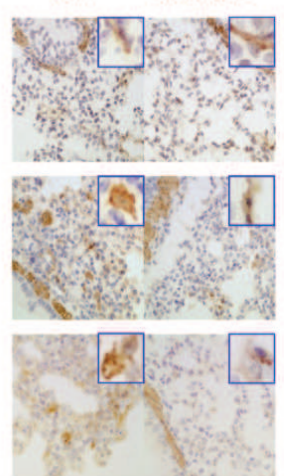

B
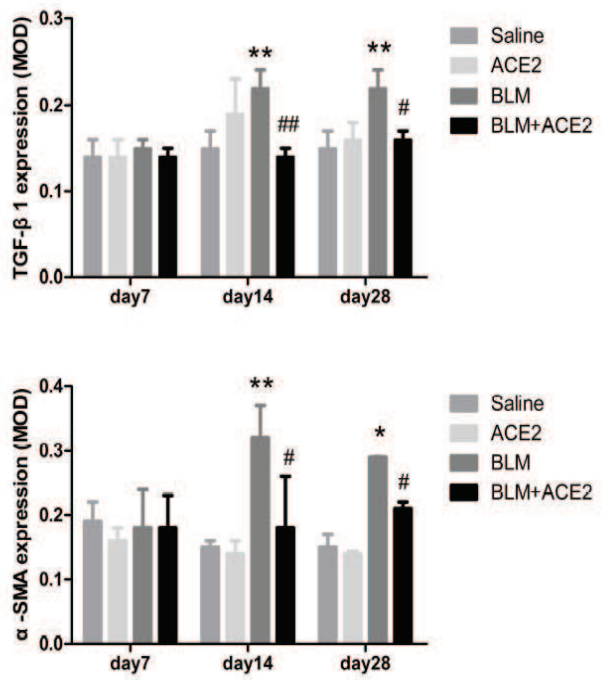

C
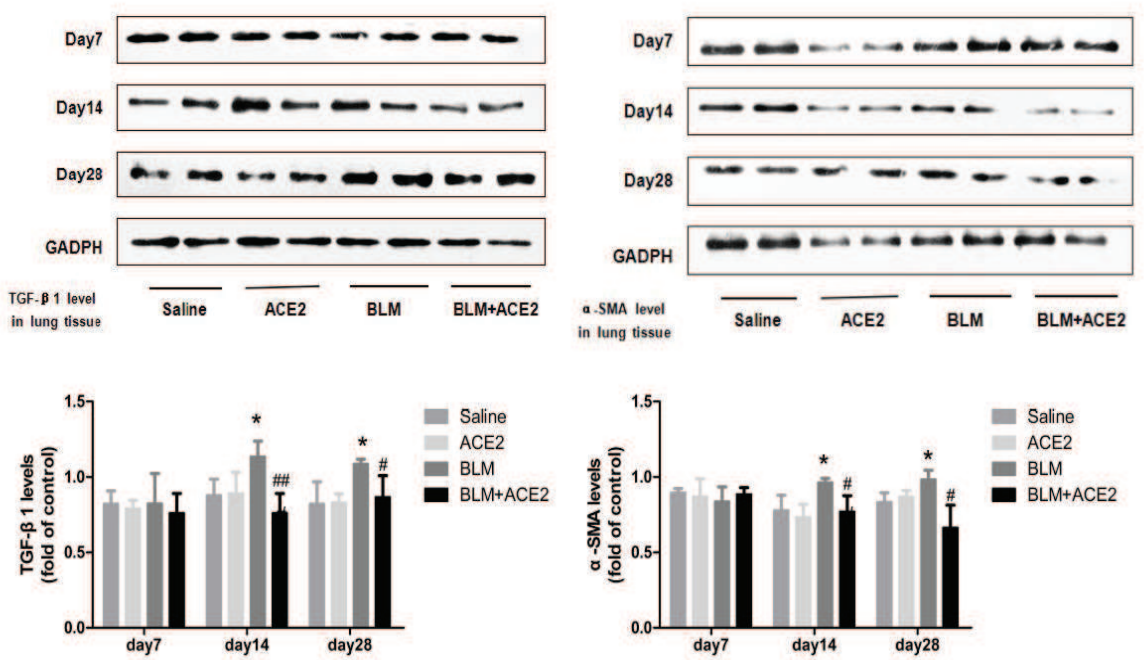

Fig. 4. ACE2 inhibited fibrotic repair in bleomycin-induced lung fibrosis. (A) In Saline group and ACE2 group, positive staining of TGF- $\beta 1$ in connective tissue and $\alpha$-SMA which strongly expressed in smooth muscles were mostly found underlying bronchial and vascular walls (400×). On day 14 and day 28 as fibrosis began to appear, patchy staining of TGF- $\beta 1$ and $\alpha$-SMA emerged in fibrotic lesions, and were both attenuated by ACE2 though still scattered in lung interstitium. (B) Semiquantitative study of TGF- $\beta 1$ and $\alpha$-SMA expression was obtained to reveal the degree of fibrogenesis. (C) Western blot analysis of TGF- $\beta$ and $\alpha$-SMA level in lung tissue. Quantitative studies comfirmed that ACE2 inhibited BLM-induced fibrogenesis. * $\mathrm{p}<0.05$ when compared with Saline group, ${ }^{* *} \mathrm{p}<0.01$ when compared with Saline group, $\# \mathrm{p}<0.05$ when compared with BLM group, \#\#p<0.05 when compared with BLM group.

ACE2 contributed to the counterregulation of the local RAS in bleomycin-induced lung fibrosis

As shown in Figure 5, local AGT expression in the lung was mainly found in endothelial cells and vascular smooth muscle cells in the Saline group. During bleomycin-induced fibrogenesis, AGT was remarkably upregulated on days 14 and 28, localized at the sites of 


\section{Cellular Physiology $\quad \begin{aligned} & \text { Cell Physiol Biochem 2015;36:697-711 } \\ & \text { Dor: 10.1159/000430131 }\end{aligned}$ \begin{tabular}{l|l|l}
\hline DOI: 10.1159/000430131 & O 2015 S. Karger AG, Basel
\end{tabular} \\ Wang et al.: ACE2 Attenuates Lung Fibrosis}

A

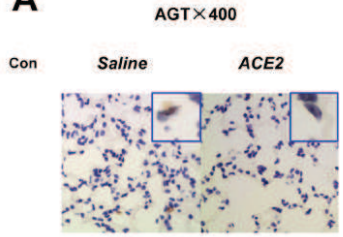

BLM BLM+ACE2
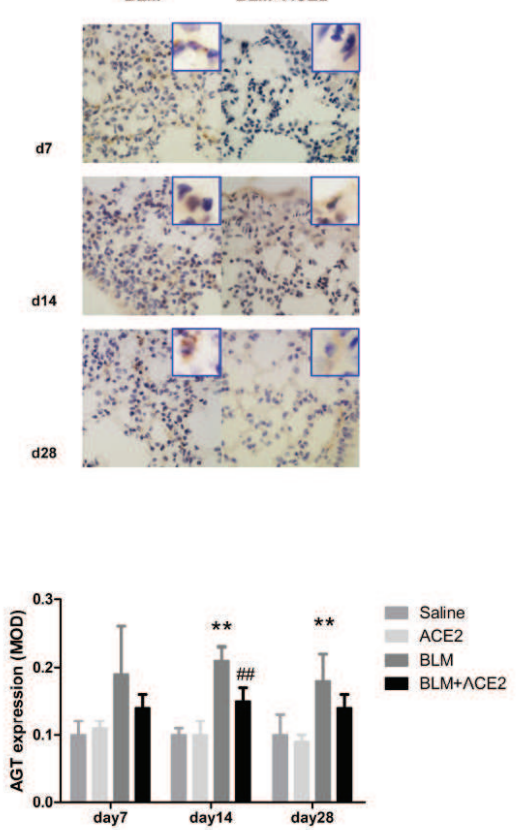

C
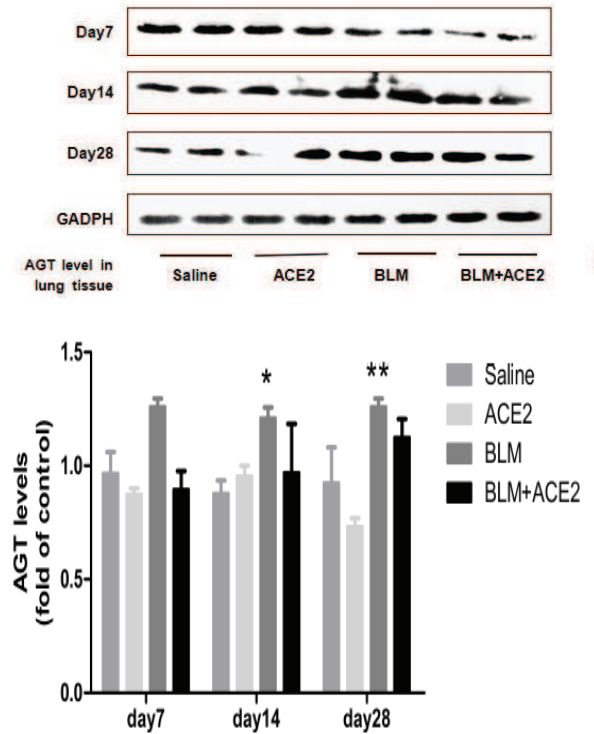

B $\quad$ ACE2 $\times 400$

Con Saline ACE2

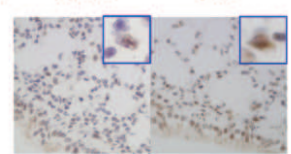

$B L M$

BLM+ACE2
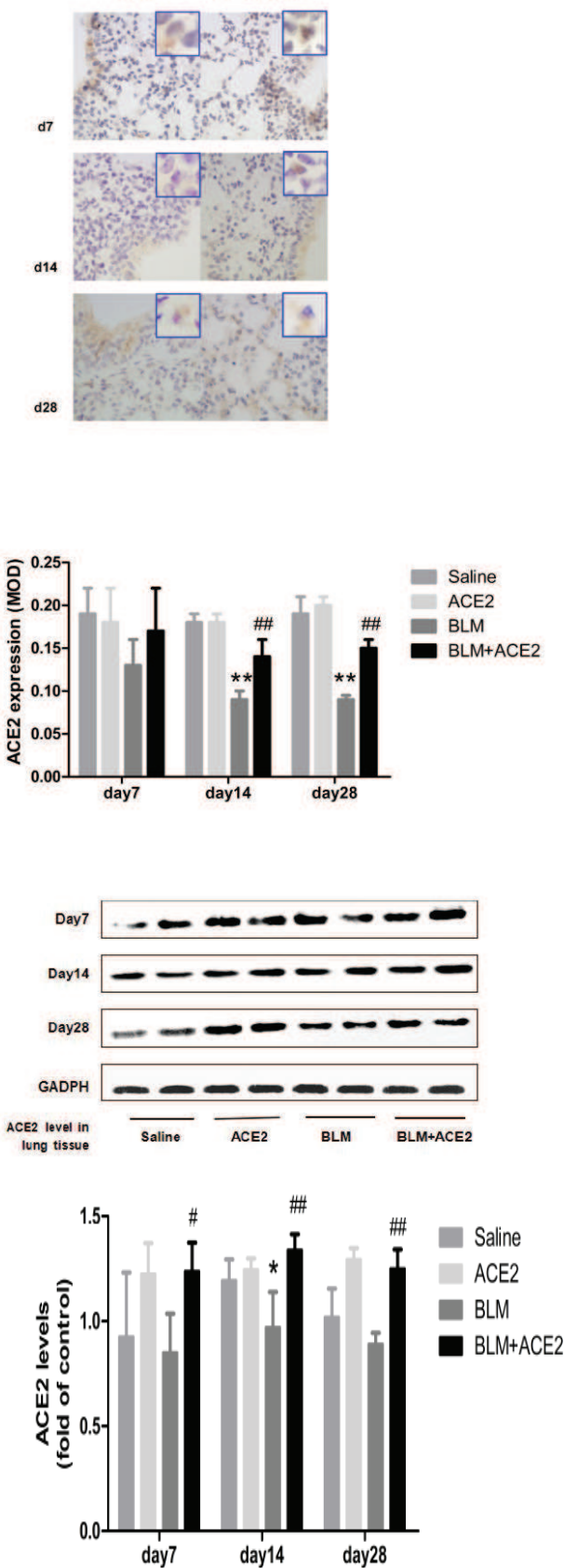

Fig. 5 ACE2 modulated local RAS in bleomycin-induced lung fibrosis (400x). (A) AGT was originally expressed in pulmonary vessels and bronchial smooth muscle. Over-expression of AGT in alveolar epithelium during bleomycin-induced lung fibrosis was significantly inhibited by ACE2 administration. (B) ACE2 expressed predominantly in vascular and bronchial wall. Relatively weak expression of ACE2 in alveolar epithelium was detected in normal lungs and was not altered by exogenous AEC2. Meanwhile loss of ACE2 


\section{Cellular Physiology Cell Physiol Biochem 2015;36:697-711

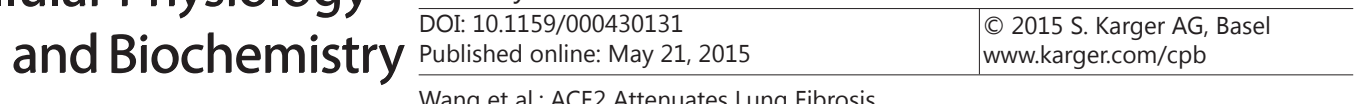

in alveolar epithelium in bleomycin-induced lung fibrosis seemed to be prevented by exogenous AEC2 intervention. (C) Western blot analysis of AGT and ACE2 level in lung tissue. Quantitative studies comfirmed that ACE2 down-regulated local RAS in lung. ${ }^{*} \mathrm{p}<0.05$ when compared with Saline group, ${ }^{* *} \mathrm{p}<0.01$ when compared with Saline group, \#p<0.05 when compared with BLM group, \#\#p<0.05 when compared with BLM group.

alveolar destruction and fibrotic foci (both $\mathrm{p}<0.05$ compared with the Saline group). Local ACE2 was immunoassayed mainly in the pulmonary vessel walls in the Saline group, and there was weak positive expression in a small proportion of epithelial cells. In the BLM group, ACE2 levels tended to decrease, especially on day $14(\mathrm{p}<0.05$ compared with the Saline group) and was scarcely stained in the parenchyma of fibrotic lungs. In the BLM+ACE2 group, AGT levels did not significantly change compared to the BLM group ( $\mathrm{p}>0.05)$. ACE2 expression in the $B L M+A C E 2$ group, in contrast, showed a relatively higher level than the BLM group (compared to the BLM group, $\mathrm{p}<0.05$ on day 7 , and $\mathrm{p}<0.01$ on days 14 and 28). Exogenous ACE2 via the tail vein did not seem to alter the protein levels of the local RAS in the ACE2 group (all p $>0.05$ compared with the Saline group at the same time point).

\section{Discussion}

IPF, a refractory and lethal disease, is a form of progressive lung fibrosis with an unknown etiology and with no regimen to improve survival. It is the most common interstitial lung disease (ILD), with the worst prognosis. The global epidemiology of IPF remains unknown, with a prevalence of 14-42.7 per 100,000 estimated in the US and an annual incidence of 7.44 per 100,000 in the U.K., which seem to be rising $[3,22]$. Patients suffer from unrelieved coughing and breathlessness, exhaustion, and a grave fear of "conscious suffocation" [1], and the progressive clinical course ultimately leads to lethal complications, such as respiratory failure, heart failure, bronchogenic carcinoma, ischemic heart disease, infection and pulmonary embolism [23]. Thus, there is an urgent need for novel therapies that can attenuate or reverse the disease process. The hallmark of IPF is usual interstitial pneumonia (UIP), radiologically and pathologically featuring bilateral, sub-pleural and basilar predominant abnormalities that are histologically characterized by fibroblast accumulation, collagen deposition and fibroblast foci [24]. Risk factors (cigarette smoking, gastroesophageal reflux disease [GERD], metal dust exposures, surfactant protein C [SFTPC] mutations, etc.) [25] are commonly associated with alveolar injury, resulting in inflammatory response, exaggerated apoptosis and the abnormal proliferation of alveolar epithelial cell during the early alveolitis stage of IPF [4, 26-28] and gradually stimulating fibrogenesis, fibroblast activation and massive collagen deposition during end-stage fibrosis.

According to the manifestations of IPF, bleomycin-induced lung fibrosis in the mouse is the most common animal model that mimics the pathologic features of IPF. In our study, we used a single dose of bleomycin injection via the tail vein to induce pulmonary fibrosis, which resulted in an early stage of epithelial apoptosis, inflammatory response, progression of fibrogenesis within 14 days and persistent fibrosis which peaked in 28 days. The pathological manifestations were in accordance with the previous studies [29]; at the same time, a more comprehensive overview was used in our study to identify the molecular processes underlying the pathogenesis of IPF.

Although there have been quite a few interventions to attenuate bleomycin-induced lung fibrosis, such as corticosteroids and immunosuppressants, it has been noted that preventing the progression of fibrosis seems to be more essential than interfering with inflammation in the early stages [30]. In our research, we assessed the treatment effects of recombinant ACE2 on lung fibrosis and found that a single intraperitoneal injection of ACE2 in bleomycin-induced lung fibrosis in mice resulted in only mild fibrosis over time. We found that ACE2 could ameliorate the progression of fibrosis, particularly from 14 to 28 days 


\section{Cellular Physiology Cell Physiol Biochem 2015;36:697-711 \\ \begin{tabular}{l|l} 
and Biochemistry $10.1159 / 000430131$ & $\begin{array}{l}\text { Do } 2015 \mathrm{~S} \text {. Karger AG, Basel } \\
\text { Published online: May 21, } 2015\end{array}$ \\
\cline { 2 - 3 }
\end{tabular}}

after administration. Our experiment indicated that ACE2 aimed to improve fibrotic tissue remodeling, thus providing a promising therapeutic target in IPF.

The local RAS in the lungs, which is involved in the pathogenesis of IPF, acts in a sophisticated paracrine/autocrine manner. Our research found that the effector proteins in the local RAS were originally expressed in the vascular endothelium and bronchial smooth muscle; in addition, AGT- or ACE2-positive cells were scattered in the alveolar walls, in accordance with previous studies showing that AGT was excessively secreted by epithelial cells in bleomycin-induced lungs, and exogenous ACE2, administered in the very early stage of fibrogenesis, could combat the effects of AGT/AngII on the lungs, resulting in relatively low levels of AGT expression in the lungs, although without statistical significance. Lo CS et al. demonstrated that AGT expression negatively regulated ACE2 levels in a mouse model [31]. Although the complete mechanism by which ACE2 affects AGT expression is not clear, our experiment demonstrated this negative-feedback loop of the local RAS. Moreover, it was detected that in fibrotic lungs, loss of ACE2 expression in epithelial cells became progressively obvious beginning on day 7, while upregulation of AGT was not evident until day 14. The changes in AGT and ACE2 expression both emerged noticeably in the region of distorted alveolar spaces and fibrotic lesions. Our findings reflected the unique condition that loss of negative balance in the local RAS (ACE2 decrease) might be more sensitive to lung injury than the activation of the positive axis (AGT increase). Therefore, this research emphasized that negative modulation of the local RAS, such as with ACE2, might play a vital role in the pathogenesis of IPF.

There is a large body of evidence from animal or cellular experiments demonstrating that local RAS activation plays a critical role in lung fibrogenesis, and for patients in the early stage of IPF, Couluris et al. proved that angiotensin receptor blockers (ARBs), such as losartan, could stabilize lung function over 12 months [32], indicating clinical applications for the inhibiting of RAS activation for IPF patients. However, medications such as angiotensin converting-enzyme inhibitors (ACEIs) or ARBs still do not show solid beneficial clinical effects on patients' long-term survival [33], and there are still no medical therapies that can slow the progression of the disease [34]. It was found that ACEIs only partially blocked AngII via ACE-dependent generation of AngII, and ARB basically inhibited the AT ${ }_{1} \mathrm{R}$-dependent pathway during local RAS activation [35]. However, ACE-independent generation of AngII in chronic lung diseases has been found to be unaffected by ACE activity $[9,36]$. Moreover, $\mathrm{AT}_{1} \mathrm{R}$ blockade by $\mathrm{ARB}$ has been associated with unopposed $\mathrm{AT}_{2} \mathrm{R}$ stimulation [37] and further increases in $\mathrm{AT}_{2} \mathrm{R}$ expression [38], while ARBs ignore the pro-inflammatory and pro-fibrotic effects in lung fibrosis via the AngII-AT ${ }_{2} \mathrm{R}$ pathway [39]. In our experiment, we stated that ACE2, as a "hub," radically modulated the aberrant activation of the local RAS, and exogenous ACE2 was able to maintain relatively stable protein levels of local ACE2 and AGT in a fibrotic stress environment, and it attenuated pathological changes in the lungs over time. Consistent with our findings, Dong B et al. [40] found that overexpression of ACE2 was superior to losartan in improving collagen accumulation in a myocardial fibrosis model. Similarly, a study conducted by Bruce D. Uhal et al. [41] indicated that ACE2's end products Ang1-7 played more effective protective roles in apoptosis of alveolar epithelial cells than saralasin. Therefore, we conclude that strengthening the negative feedback by ACE2, rather than partially blocking the positive loop of the local RAS, might claim priority in treating IPF.

Because IPF occurs predominantly in middle age, it is presumed that the accumulation of subclinical micro-injuries to the genetically susceptible alveolar epithelium gradually triggers the disease [4]. It has been reported that epithelial injury promotes fibrogenesis generally along two pathways: the epithelial cell pathway and the inflammation pathway [42]. In the epithelial cell pathway, exaggerated epithelial apoptosis is induced, followed by aberrant proliferation of type II epithelial cells. Among these activated type II alveolar epithelial cells, some differentiate into type I alveolar epithelial cells for re-alveolarization, and some cells, influenced by pro-fibrotic cytokines, undergo epithelial-mesenchymal transitions (EMTs) to transform into fibroblast-like cells for fibrogenesis, while other cells exhibit squamous metaplasia, together contributing to alveolar architecture destruction 


\section{Cellular Physiology Cell Physiol Biochem 2015;36:697-711

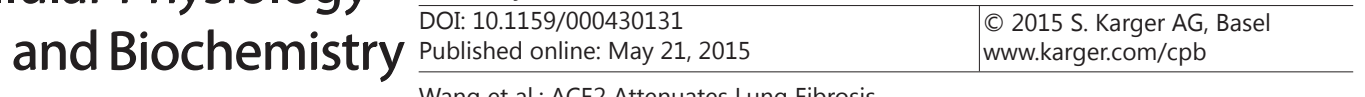

$[43,44]$. In the inflammatory cell pathway, multiple cells, mainly macrophages, neutrophils, and lymphocytes, infiltrate the alveolar septa and alveolar space; alveolitis can resolve spontaneously during disease progression [6]. Although inflammation in IPF is non-specific, pro-inflammatory cytokines (e.g., IL-1 $\beta$, IL-6, IL-8, IL-18, TNG- $\alpha$, etc.), released during the alveolitis stage, also play pro-apoptotic and pro-fibrotic roles, contributing to fibrogenesis $[45,46]$.

Local RAS activation in IPF is essential to the pathogenesis of epithelial injury in those two ways. AngII is a pro-apoptotic cytokine for alveolar epithelial cells [47]. It was found that epithelial apoptosis could be completely inhibited by neutralizing antibodies specific for AngII [10]; Yuko Waseda et al. [39] indicated that ARBs for bleomycin-induced pulmonary fibrosis could remarkably decrease both inflammatory cells and pro-inflammatory cytokines in bronchoalveolar lavage fluid (BALF). In our research, the apoptosis index, assayed by the TUNEL method in fibrotic lungs, increased and reached a plateau from day 7 , and most apoptotic cells were morphologically similar to epithelial cells. We observed that ACE2 inhibited cell apoptosis at all time points, which supported a role for ACE2 as an antiapoptotic agent for epithelial cells in bleomycin-induced lung fibrosis. However, TUNEL assay could only detect non-specific DNA fragmentation due to necrosis $[48,49]$. The apoptotic cell population in the late stage of IPF could possibly include damaged epithelial cells, inflammatory cells cleared during spontaneous resolution of inflammation, myofibroblasts eliminated in repair processes, etc. [50]. We believe that our results preferably showed the protective role of ACE2 in cell apoptosis in the early stage of IPF pathogenesis. Further study of ACE2 therapy, measuring the rates of apoptosis of different cell types, is warranted.

In contrast, LCA (LCA/CD45) staining of inflammatory cells sustained high-level expression in fibrotic lungs, associated with massive cell infiltration, which increased from day 7 to day 14, and tended to decrease from day 14 to day 28, and ACE2 presented antiinflammatory effects. Because epithelial cell apoptosis could occur in the absence of an inflammatory response [50], we proved that ACE2 possessed integrated protective effects on both the epithelial cell pathway and the inflammation pathway which seemed relatively independent. For further evaluation, we used surfactant protein A (SP-A) to identify type II alveolar epithelial cells as a sensitive marker for the early detection of epithelial injury $[51,52]$. The proliferation response of type II epithelial cells coincided with apoptosis in bleomycin-induced mice and was attenuated by ACE2 in the early stage. In the sub-acute phase, SP-A expression decreased over time, while apoptosis persisted. Because SP-A is also considered a biomarker for the prediction of survival in IPF [53], our study revealed that ACE2 was able to maintain more reserve epithelial cells in the late period of the disease, which could hopefully provide beneficial effects on IPF prognosis.

It is the fibrogenesis that distinguishes IPF from other chronic lung diseases [7, 14]. It is well known that TGF- $\beta 1$ is one of the strongest pro-fibrotic cytokines. In the early stage of lung fibrosis, inflammatory cells are the main source of TGF- $\beta 1$ [54-57], and during disease progression, fibroblasts mainly contribute to increasing accumulation of TGF- $\beta 1$. Therefore, TGF- $\beta 1$ has been indicated to be a fibrosis-associated biomarker [58]. AngII in the local RAS plays a pro-fibrotic role through the "AGT-TGF- $\beta 1$ autocrine loop," thus amplifying the effects of TGF- $\beta 1$ on EMT, fibroblast proliferation, fibroblast-to-myofibroblast transdifferentiation and excessive collagen deposition. Qian YR et al. proposed that ACE2 could block TGF$\beta 1$-induced EMT in alveolar epithelial cells [59], and Ying Meng et al. discovered that overexpression of ACE2 could inhibit the expression of TGF- $\beta 1$ from human fibroblasts, and it suppressed cell proliferation and collagen synthesis [60]. Some in vivo experiments resulted in similar findings that overexpression or administration of ACE2 could inhibit bleomycin-induced lung fibrosis in animal models $[18,61]$. Our experiment revealed that ACE2 presented as an anti-fibrotic agent to weaken the overexpression of TGF- $\beta 1$ in the late stage of bleomycin-induced lung fibrosis. Moreover, myofibroblasts, the primary effector cells responsible for increasing extracellular matrix deposition and traction bronchiectasis $[62,63]$, were marked by $\alpha$-SMA in our experiment and were discovered to be inhibited by ACE2 administration. We believe that ACE2 might play a preventive role in severe lung 


\section{Cellular Physiology Cell Physiol Biochem 2015;36:697-711 \\ and Biochemistry \begin{tabular}{l|l}
${ }$ Published online: May 21, $2015 }$ & $\begin{array}{l}\text { C 2015 S. Karger AG, Basel } \\
\text { www.karger.com/cpb }\end{array}$ \\
\hline
\end{tabular}}

Wang et al.: ACE2 Attenuates Lung Fibrosis

structure derangement in end-stage fibrosis.

In conclusion, our research provided comprehensive evidence that ACE2 attenuated bleomycin-induced lung fibrosis as an anti-inflammatory, anti-apoptotic and anti-fibrotic agent and that ACE2 might be a promising therapeutic target for IPF.

\section{Acknowledgments}

We would like to thank Beijing Hospital, Laboratory Animal Department and Department of Pathology of Peking University Health Science Center for providing excellent facilities to conduct our experimental studies.

\section{Disclosure Statement}

The authors have no conflicts of interest to declare.

\section{References}

1 Swigris JJ, Stewart AL, Gould MK, Wilson SR: Patients' perspectives on how idiopathic pulmonary fibrosis affects the quality of their lives. Health Qual Life Out DOI: 10.1186/1477-7525-3-61.

2 Nho RS: Current concept for the pathogenesis of idiopathic pulmonary fibrosis. Clin Res Pulmono 2013;1:1006-1008.

3 Navaratnam V1, Fleming KM, West J, Smith CJ, Jenkins RG, Fogarty A, Hubbard RB: The rising incidence of idiopathic pulmonary fibrosis in the U.K. Thorax 2011;66:462-467.

4 Selman M, Pardo A: Role of epithelial cells in idiopathic pulmonary fibrosis. Proc Am Thorac Soc 2006;3:364-372.

5 Wallace WA, Howie SE: Immunoreactive interleukin 4 and interferon-gamma expression by type II alveolar epithelial cells in interstitial lung disease. J Pathol 1999;187:475-480.

6 Semenzato G, Adami F, Maschio N, Agostini C: Immune mechanisms in interstitial lung diseases. Allergy 2000;15:1103-1120.

7 Beers MF, Morrisey EE: The three R's of lung health and disease: repair, remodeling, and regeneration. J Clin Invest 2011;121:2065-2073.

8 Li X, Molina MM, Abdul HA, Ramirez J, Serrano MA, Xaubet A, Uhal BD: Extravascular sources of lung angiotensin peptide synthesis in idiopathic pulmonary fibrosis. Am J Physiol Lung Cell Mol Physiol 2006;291:887-895.

9 Uhal BD, Dang MT, Li X, Abdul HA: Angiotensinogen gene transcription in pulmonary fibrosis. Int J Pept DOI:10.1155/2012/875910.

10 Wang R, Alam G, Zagariya A, Gidea C, Pinillos H, Lalude O, Choudhary G, Oezatalay D, Uhal BD: Apoptosis of lung epithelial cells in response to TNF- $\alpha$ requires angiotensin II generation de novo. J Cell Physiol 2000;185:253-259.

11 Guo L, Richardson KS, Tucker LM, Doll MA, Hein DW, Arteel GE: Role of the renin-angiotensin system in hepatic ischemia reperfusion injury in rats. Hepatology 2004;40:583-589.

12 Chipitsyna G, Gong Q, Gray CF, Haroon Y, Kamer E, Arafat HA: Induction of monocyte chemoattractant protein-1 expression by angiotensin II in the pancreatic islets and beta-cells. Endocrinology 2007;148:2198-2208.

13 Benigni A, Cassis P, Remuzzi G: Angiotensin II revisited: new roles in inflammation, immunology and aging. Embo Mol Med 2010;2:247-257.

14 Uhal BD, Kim JK, Li X, Molina MM: Angiotensin-TGF-beta 1 crosstalk in human idiopathic pulmonary fibrosis: antocrine mechanisms in myofibroblasts and macrophages. Curr Pharm Des 2007;13:1247-1256.

15 Ferrario CM: ACE2: more of Ang-(1-7) or less Ang II? Curr Opin Nephrol Hypertens 2011;20:1-6.

16 Simões e Silva AC, Silveira KD, Ferreira AJ, Teixeira MM: ACE2, angiotensin-(1-7) and Mas receptor axis in inflammation and fibrosis. Brit J Pharmacol 2013;169:477-492. 


\section{Cellular Physiology Cell Physiol Biochem 2015;36:697-711

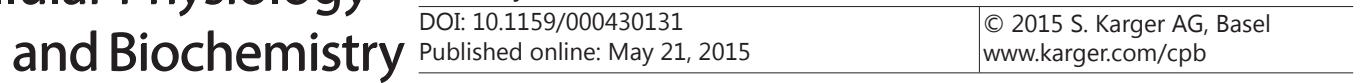

Wang et al.: ACE2 Attenuates Lung Fibrosis

17 Ocaranza MP, Jalil JE: Protective role of the ACE2/Ang-(1-9) axis in cardiovascular remodeling. Int J Hypert DOI: $10.1155 / 2012 / 594361$.

18 Li X, Maria MM, Abdul HA, Uhal V, Xaubet A, Uhal BD: Angiotensin converting enzyme-2 is protective but downregulated in human and experimental lung fibrosis. Am J Physiol Lung Cell Mol Physiol 2008;295:178-185.

19 Szapiel SV, Elson NA, Fulmer JD, Hunninghake GW, Crystal RG: Bleomycin-induced interstitial pulmonary diseases in the nude, athymic mouse. Am Rev Resp Dis 1979;120:893-899.

20 Prasad K, Prabhu GK: Image analysis tools for evaluation of microscopic views of immunohistochemically stained specimen in medical research-a review. J Med Syst 2012;36:2621-2631.

21 Wang CJ, Zhou ZG, Holmqvist A, Zhang H, Li Y, Adell G, Sun XF: Survivin expression quantified by image proplus compared with visual assessment. Appl Immunol 2009;17:530-535.

22 Raghu G, Weycker D, Edelsberg J, Bradford WZ, Oster G: Incidence and prevalence of idiopathic pulmonary fibrosis. Am J Respir Cri Care Med 2006;174:810-816.

23 Panos RJ, Mortenson RL, Niccoli SA, King TE Jr: Clinical deterioration in patients with idiopathic pulmonary fibrosis: causes and assessment. Am J Med 1990; 88:396-404.

24 Wells AU: The revised ATS/ERS/JRS/ALAT diagnostic criteria for idiopathic pulmonary fibrosis (IPF)practical implications. Respir Res DOI: 10.1186/1465-9921-14-80.

25 García SC, Buendía RI, Fernández-Plataa MR, Navarroa C, Pérez-Padillaa R, Vargasa MH, Loydb JE, Selmana M: Familial pulmonary fibrosis is the strongest risk factor for idiopathic pulmonary fibrosis. Respir Med 2011;105:1902-1907.

26 Harari S, Caminati A: IPF: new insight on pathogenesis and treatment. Allergy 2010;65:537-553.

27 Jin HL, Dong JC: Pathogenesis of idiopathic pulmonary fibrosis: from initial apoptosis of epithelial cells to lung remodeling. Chin Med J 2011;124:4330-4338.

28 Wolters PJ, Collard HR, Jones KD: Pathogenesis of idiopathic pulmonary fibrosis. Ann Rev Pathol DOI: 10.1146/annurev-pathol-012513-104706.

29 Moeller A, Askc K, Warburtond D, Gauldiec J, Kolba M: The bleomycin animal model: a useful tool to investigate treatment options for idiopathic pulmonary fibrosis? Int J Biochem Cell Biol 2008;40:362-382.

30 Scotton CJ, Chambers RC: Bleomycin revisited: towards a more representative model of IPF? Am J Physiol Lung Cell Mol Physiol 2010;299:439-441.

31 Lo CS, Liu F, Shi Y, Maachi H, Chenier I, Godin N, Filep JG, Ingelfinger JR, Zhang SL, Chan JS: Dual RAS blockade normalizes angiotensin-converting enzyme-2 expression and prevents hypertension and tubular apoptosis in Akita angiotensinogen-transgenic mice. Am J Physiol Renal Physiol 2012;302:840-852.

32 Couluris M, Kinder BW, Xu P, Gross-King M, Krischer J, Panos RJ: Treatment of idiopathic pulmonary fibrosis with losartan: a pilot project. Lung 2012;190:523-527.

33 Nadrous HF, Olson EJ, Douglas WW, Decker PA, Nadrous JH: Idiopathic pulmonary fibrosis: impact of angiotensin converting enzyme inhibitors and HMG-CoA reductase inhibitors on survival. Chest DOI:10.1378/chest.124.4_MeetingAbstracts.116S-a.

34 Hunninghake GM: A new hope for idiopathic pulmonary fibrosis. N Engl J Med 2014;370:2142-2143.

35 Uhal BD, Li X, Piasecki CC, Molina-Molina M: Angiotensin signalling in pulmonary fibrosis. J Biochem Cell Biol 2012;44:465-468.

36 Wang T, Han SX, Zhang SF, Ning YY, Chen L, Chen YJ, He GM, Xu D, An J, Yang T, Zhang XH, Wen FQ: Role of chymase in cigarette smoke-induced pulmonary artery remodeling and pulmonary hypertension in hamsters. Respir Res DOI:10.1186/1465-9921-11-36.

37 Sipahi I, Debanne SM, Rowland DY, Simon DI, Fang JC: Angiotensin-receptor blockade and risk of cancer: meta-analysis of randomised controlled trials. Lancet DOI:10.1016/S1470-2045(10)70106-6.

38 Mii A, Shimizu A, Masuda Y, Ishizaki M, Kawachi H, Iino Y, Katayama Y, Fukuda Y: Angiotensin II receptor blockade inhibits acute glomerular injuries with the alteration of receptor expression. Lab Invest 2009;89:164-177.

39 Waseda Y, Yasui M, Nishizawa Y, Inuzuka K, Takato H, Ichikawa Y, Tagami A, Fujimura M, Nakao S: Angiotensin II type 2 receptor antagonist reduces bleomycin-induced pulmonary fibrosis in mice. Respir Res 2008;9:43. 


\section{Cellular Physiology Cell Physiol Biochem 2015;36:697-711

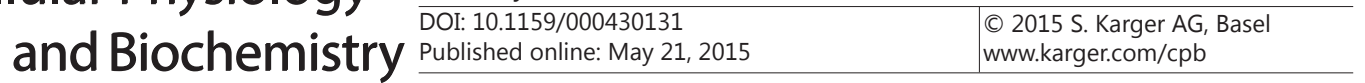

Wang et al.: ACE2 Attenuates Lung Fibrosis

40 Dong B, Yu QT, Dai HY, Gao YY, Zhou ZL, Zhang L, Jiang H, Gao F, Li SY, Zhang YH, Bian HJ, Liu CX, Wang N, Xu H, Pan CM, Song HD, Zhang C, Zhang Y: Angiotensin-converting enzyme-2 over expression improves left ventricular remodeling and function in a rat model of diabetic cardiomyopathy. J Am Coll Cardiol 2012;59:739-747.

41 Uhal BD, Nguyen H, Dang M, Gopallawa I, Jiang J, Dang V, Ono S, Morimoto K: Abrogation of ER stressinduced apoptosis of alveolar epithelial cells by Angiotensin1-7. Am J Physiol Lung Cell Mol Physiol 2013;305:33-41.

42 King TE Jr, Pardo A, Selman M: Idiopathic pulmonary fibrosis. Lancet 2011;378:1949-1961.

43 Harari S, Caminati A: IPF: new insight on pathogenesis and treatment. Allergy 2010;65:537-553.

44 Kawanami O, Ferrans VJ, Crystal RG: Structure of alveolar epithelial cells in patients with fibrotic lung disorders. Lab Invest 1982;46:39-53.

45 Biswas R, Bunderson-Schelvan M, Holian A: Potential role of the inflammasome-derived inflammatory cytokines in pulmonary fibrosis. Pulm Med DOI: 10.1155/2011/105707.

46 Bonfield TL, Panuska JR, Konstan MW, Hilliard KA, Hilliard JB, Ghnaim H, Berger M: Inflammatory cytokines in cystic fibrosis lungs. Am J Respir Crit Care Med 1995;52:2111-2118.

47 Uhal BD: Apoptosis in lung fibrosis and repair. Chest 2002;122:293-298.

48 Dong Z, Saikumar P, Weinberg JM, Venkatachalam MA: Internucleosomal DNA cleavage triggered by plasma membrane damage during necrotic cell death. Involvement of serine but not cysteine proteases. Am J Pathol 1997;151:1205-1213.

49 Schulze-osthoff K, Bantel H: Necrosis versus apoptosis in acetaminophen-induced hepatotoxicity. Hepatology 2011;1053:1070.

50 Thannickal VJ, Horowitz JC: Evolving concepts of apoptosis in idiopathic pulmonary fibrosis. Proc Am Thorac Soc 2006;3:350-356.

51 Phelps DS, Umstead TM, Mejia M, Carrillo G, Pardo A, Selman M: Increased surfactant protein-A levels in patients with newly diagnosed idiopathic pulmonary fibrosis. Chest 2004;2:67-625.

52 Greene KE, King TE Jr, Kuroki Y, Bucher-Bartelson B, Hunninghake GW, Newman LS, Nagae H, Mason RJ: Serum surfactant proteins-A and -D as biomarkers in idiopathic pulmonary fibrosis. Eur Respir J 2002;3:439-446.

53 McCormack FX, King TE Jr, Bucher BL, Nielsen L, Mason RJ: Surfactant protein A predicts survival in idiopathic pulmonary fibrosis. Am J Respir Crit Care Med 1995;152:751-759.

54 Khalil N, Bereznay 0, Sporn M, Greenberg AH: Macrophage production of transforming growth factor $\beta 1$ and collagen synthesis in chronic pulmonary inflammation. J Exp Med 1989;170:723.

55 Kelly M1, Kolb M, Bonniaud P, Gauldie J: Re-evaluation of fibrogenic cytokines in lung fibrosis. Curr Pharm Des 2003;9:39-49.

56 Meng Y, Yu CH, Li W, Li T, Luo W, Huang S, Wu PS, Cai SX, Li X: Angiotensin-converting enzyme2/ angiotensin-(1-7)/Mas axis protects against lung fibrosis by inhibiting the MAPK/NF- $\kappa B$ pathway. Am J Respir Cell Mol Bio DOI: 10.1165/rcmb.2012-04510C.

57 Coker RK, Laurent GJ: Pulmonary fibrosis: Cytokines in balance. Eur Respir J 1998;11:1218.

58 Lee TC, Gold LI, Reibman J, Aston C, Bégin R, Rom WN, Jagirdar J: Immunohistochemical localization of transforming growth factor-beta and insulin-like growth factor-I in asbestosis in the sheep model. Int Arch Occup Environ Health 1997;69:157-164.

59 Qian YR, Guo Y, Wan HY, Fan L, Feng Y, Ni L, Xiang Y, Li QY: Angiotensin-converting enzyme 2 attenuates the metastasis of non-small cell lung cancer through inhibition of epithelial-mesenchymal transition. Oncol Rep 2013;29:2408-2414.

60 Fernandez IE, Eickelberg 0: The impact of TGF- $\beta$ on lung fibrosis: from targeting to biomarkers. Proc Am Thrac Soc 2012;9:111-116.

61 Shenoy V, Ferreira AJ, Qi Y, Fraga-Silva RA, Díez-Freire C, Dooies A, Jun JY, Sriramula S, Mariappan N, Pourang D, Venugopal CS, Francis J, Reudelhuber T, Santos RA, Patel JM, Raizada MK, Katovich MJ: The angiotensin-converting enzyme 2/angiogenesis-(1-7)/Mas axis confers cardiopulmonary protection against lung fibrosis and pulmonary hypertension. Am J Respir Crit Care Med 2010;182:1065-1072.

62 Scotton CJ, Chambers RC: Molecular targets in pulmonary fibrosis: the myofibroblast in focus. Chest 2007;132:1311-1321.

63 Sem HP: The myofibroblast in pulmonary fibrosis. Chest 2002;122:286-289. 